\title{
Adsorption of Methane and Carbon Dioxide on Gas Shale and Pure Mineral Samples By Rob Heller and Mark Zoback
}

\author{
Department of Geophysics, Stanford University, Stanford, CA
}

\section{ABSTRACT}

We have measured methane and carbon dioxide adsorption isotherms at $40^{\circ} \mathrm{C}$ on gas shale samples from the Barnett, Eagle Ford, Marcellus and Montney reservoirs. Carbon dioxide isotherms were included to assess its potential for preferential adsorption, with implications for its use as a fracturing fluid and/or storage in depleted shale reservoirs. To better understand how the individual mineral constituents that comprise shales contribute to adsorption, measurements were made on samples of pure carbon, illite and kaolinite as well. We were able to successfully fit all adsorption data for both gases in accordance with a Langmuir isotherm model. Our results show carbon dioxide to have approximately 2-3 times the adsorptive capacity of methane in both the pure mineral constituents and actual shale samples. In addition to obvious microstructural and compositional differences between real rocks and pure minerals, we hypothesize that water adsorption plays an important role in regulating surface area availability for other molecules to adsorb. The resultant volumetric swelling strain was also measured as a function of pressure/adsorption. We observe both clay and pure carbon to swell an amount that is approximately linearly proportional to the amount of adsorption.

\section{INTRODUCTION}

Gas shales are complex rocks, characterized by heterogeneity in composition and structure at all scales. Similarly, the production of natural gas from shales is controlled by phenomena acting at many different scales, as has been reviewed by several authors (Bustin et al., 2008; Loucks et al., 2009; Wang and Reed, 2009; Sondergeld, et al., 2010). One potentially significant property impacting production from these reservoirs is the adsorption of methane, which is controlled by the composition and microstructure of the rock. By storing gas in a dense, 
32 liquid-like adsorbed phase, the overall storage capacity of the rock is enhanced relative to if there 33 were a free phase alone. Moreover, the release of this adsorbed phase is pressure dependent. As a 34 reservoir is depleted, the adsorbed phase is freed, providing not just additional gas for production 35 but helping to sustain pressure (and perhaps open pore throats for fluid flow) as well. While 36 adsorption allows for larger quantities of gas to be in place and possibly produced, factors such as desorption pressure, kinetics, and alteration of effective stresses makes it difficult to know if desorbed gas will contribute significantly to production.

In an effort to better understand the role of adsorption on production from gas shales, numerous authors have made valuable contributions to the literature through laboratory studies over the last 25 years. Schettler et al. (1991) performed experiments on pure clay, carbon and quartz minerals in addition to Devonian shales in an attempt to shed light on some of the factors affecting adsorption. They noted the significant adsorptive capacity of all of these minerals when measured individually. In addition, they found some cases in which the shape of the shale adsorption isotherm was best explained by adsorption on carbon (a proxy for kerogen), while others were better explained by illite adsorption. Similarly, Lu et al. (1995) measured the adsorptive capacity of several Devonian shale samples and pure illite. They concluded that while total organic content (TOC) played a first order role in the adsorptive capacity of their samples, illite was also responsible for significant gas storage, particularly in samples with little TOC.

More recent efforts have reached quite similar conclusions to previous studies. Ross and Bustin (2008) performed a laboratory investigation of the impact of composition and pore structure on total storage capacity in gas shales. In addition to carbon, they measured significant microporosity in clay minerals, particularly illite and montmorillonite. Chalmers and Bustin

54 (2008) studied the impact of kerogen type and other geochemical properties on adsorption. They 55 found that types I, II and II kerogen are all capable of equally significant amounts of adsorption, but for differing reasons. Furthermore, they highlighted complexities associated with water content competing with adsorption sites in some cases (but not others) depending on

58 geochemical composition and pore structure.

In addition to methane, there have been several studies highlighting the adsorptive capacity of carbon dioxide in gas shales. Nuttall et al. (2005) measured $\mathrm{CH}_{4}$ and $\mathrm{CO}_{2}$ adsorption 61 on Devonian black shales in order to assess the potential for enhanced recovery or sequestration. 62 They found $\mathrm{CO}_{2}$ to have a adsorption capacity approximately 5 times greater than that of $\mathrm{CH}_{4}$. 
63 Similarly, Kang et al. (2010) studied the adsorption of both gases on two samples from the

64 Barnett shale, finding $\mathrm{CO}_{2}$ to adsorb 5-10 times more than $\mathrm{CH}_{4}$.

While ubiquitous in the coalbed methane literature, there is very limited data available to predict the accompanying volumetric strain caused by desorption during production or

67 adsorption during gas injection. Lin et al. (2010) measured volumetric swelling strain resulting from adsorption of $\mathrm{N}_{2}, \mathrm{CH}_{4}$ and $\mathrm{CO}_{2}$ in coal samples. They found roughly a linear relationship between swelling strain and adsorption. Similarly, Hol et al. (2011) studied the link between adsorption, swelling and stress in coal. Their results also show a linear relationship between adsorption and swelling. Moreover, they demonstrate the quantity of adsorption/desorption at a given pressure to be significantly influenced by the magnitude of external stress on the rock. Several authors have suggested the potential importance of adsorption-induced deformation in the context of gas shales (Cui et al., 2009; Ross and Bustin, 2007), however, no efforts have directly addressed the topic to date.

In this study, we extend these previous works and investigate the adsorption of $\mathrm{CH}_{4}$ and $\mathrm{CO}_{2}$ on various shale and pure mineral samples in the laboratory. Samples from four different formations were studied, as well as pure carbon, illite and kaolinite. Using the methods described below, we measured the adsorption of $\mathrm{CH}_{4}$ and $\mathrm{CO}_{2}$ on both shale samples and pure minerals. In a triaxial apparatus, the resultant volumetric swelling strain associated with adsorption is measured. Our overall objective is to further the effort toward understanding adsorption in gas

83 production from gas shales.

\section{SAMPLE DESCRIPTION}

Experiments were first carried out on pure carbon and clay materials. Activated carbon

89 kerogen. Kaolinite and illite samples were obtained from the Clay Mineral Society and sold to us as pure clay samples. Both $\mathrm{CH}_{4}$ and $\mathrm{CO}_{2}$ adsorption isotherms were measured for each of these materials. Following these experiments, the adsorption of $\mathrm{CH}_{4}$ and $\mathrm{CO}_{2}$ was measured on gas

92 shale samples from the Barnett, Marcellus, Eagle Ford and Montney reservoirs. To the degree 93 possible, samples of representative mineralogical composition were selected from each of these 
94 shales. The Barnett sample was highest in TOC (>5\%) and had a relatively high clay content 95 (37.4\%) as well. The Montney sample and Eagle Ford samples had a similar amount of TOC 96 (2.0\% and $1.8 \%$, respectively), but the Montney sample had much more clay and quartz whereas 97 the Eagle Ford was mostly carbonate (>70\%). The Marcellus sample was lowest in TOC (1.2\%) 98 and had the highest amount of clay ( $50 \%)$. A complete description of the mineralogy of these 99 samples is provided in Table 1.

100 In addition to mineralogy, Rock Eval Pyrolisis data was gathered on three of the four 101 samples. This data is also presented in tabulated format in Table 1. Rock Eval Pyrolisis involves 102 heating a small amount of ground up sample at a constant rate $\left(5^{\circ} \mathrm{C} / \mathrm{min}\right.$, in this case $)$, and 103 measuring the hydrocarbons produced from the sample as a function of temperature. The S1 and

$104 \mathrm{~S} 2$ peaks quantify the amount of hydrocarbon thermally extracted at approximately $300^{\circ} \mathrm{C}$ and $105550^{\circ} \mathrm{C}$, respectively. S1 essentially indicates that amount of free hydrocarbons (gas or oil)

106 present in the sample, while S2 is a better indication of hydrocarbon generation potential upon

107 further heating and burial. S3 quantifies the amount of $\mathrm{CO}_{2}$ relieved from the organic matter 108 during pyrolisis of kerogen, and is indicative of the amount of oxygen in the kerogen. The Tmax

109 temperature indicates that temperature at which the S2 peak reaches a maximum, which serves as 110 an indication of the maturation stage of the organic matter. The hydrogen index (HI) and oxygen 111 index (OI) can be calculated from this data, and are typically used to characterize the origin of 112 the organic matter. All of this information can be combined to delineate whether the sample lies 113 within the immature, oil, condensate or dry gas window (Peters and Moldowan, 1993). Of the 114 three samples tested, only one lies conclusively within the dry gas window (Eagle Ford 127). 115 The Barnett 31 and Marcellus samples lie within the condensate and late-oil windows, 116 respectively.

3. METHODOLOGY \& BACKGROUND

\subsection{Adsorption Measurements}


125 the isotherm gives insight into pore structure and surface properties of the material. In general,

126 the more surface area and the stronger the adsorbate-adsorbent interaction energy, the greater the

127 amount of adsorption. However, pore size distribution also plays an important role. As pores

128 become smaller and smaller, molecules residing within such pores become increasingly more

129 impacted by the enclosing surfaces on all sides. In other words, the interaction energy from

130 multiple surfaces coalesce, resulting in an overall increase in attraction relative to a free surface.

131 Thus, materials with a large micropore volume are generally very adsorptive. When performing

132 calculations or making inferences about pore structure and surface area from adsorption

133 isotherms, it is important to distinguish between these two distinctly different mechanisms

134 (surface adsorption versus micorpore volume filling). However, it is worth keeping in mind that

135 the net effect is exactly the same: molecules are stored in a denser phase relative to the free gas 136 phase.

137 The experiments reported here were performed on crushed samples with a particle size

138 between 50 and 150 microns. While it is possible to perform adsorption experiments on intact

139 core samples, the time required to reach equilibrium would be prohibitively long due to the

140 extremely low permeability of shales (Heller et al, 2013). Therefore, measuring adsorption on

141 crushed samples is preferred. Approximately 40 grams of sample was used for each experiment.

142 After crushing, samples were placed in a vacuum oven at $40^{\circ} \mathrm{C}$ until constant mass was achieved.

143 The temperature was chosen so as to be above the boiling point of water in near vacuum

144 conditions, but not so high as to remove clay-bound water and alter the clay properties. Once

145 dried, the sample was loaded into the sample cell and again placed under vacuum to remove

146 water and gas that may have contaminated the sample during loading.

147 Procedures for measuring adsorption are well established, and can generally fall into the

148 category of either mass-based or volumetric-based methods. Mass-based methods employ the use

149 of a microbalance to directly measure the change in sample mass associated with adsorption, and

150 are very commonly used in material science. The advantage of mass-based methods is a very

151 high degree of accuracy, with the trade-off being the need to use very small sample sizes. Given

152 the heterogeneity of rocks, the oil and gas industry has generally favored the volumetric method

153 (as used in this study), which allows us to use much larger sample volumes.

154 The volumetric method is based on Boyle's law, and is very similar to porosity

155 measurements using pycnometry. The system consists of two chambers (termed the reference 
156 cell and sample cell) separated by a valve, all placed within a controlled temperature bath, as

157 shown in Figure 1. The reference cell volume, $V_{R}$, is a known value, calibrated against the

158 volume of carefully machined aluminum plugs. The crushed particles are loaded into the sample

159 cell and the void volume, $V_{S}$, (comprised of space within lines, between particles and particle

160 porosity) is determined via multiple expansions of helium from the reference cell volume, $V_{R}$.

161 Each expansion involves first pressurizing the reference cell, and quantifying the number of

162 molecules loaded into the cell as follows:

$163 \quad n_{\text {total }}=\frac{P_{1} V_{R}}{Z_{1} R T_{1}}$

164 where $V_{R}$ is the reference cell volume, $P_{1}$ the pressure, $Z_{1}$ the compressibility factor, $R$ the

165 universal gas constant and $T_{1}$ is the temperature which was that of the oil bath, set to $40^{\circ} \mathrm{C}$. The

166 valve separating the reference cell and sample cell is then opened, allowing the gas to expand

167 into the void volume of the sample cell. By selecting what is assumed to be a non-adsorbing gas

168 for this process (helium), the subsequent pressure drop once the valve is opened is due to void

169 volume filling. Therefore the number of free molecules in the system is unchanged, and the void

170 volume of the sample cell can be calculated as follows:

$171 \quad V_{S}=\frac{n_{\text {total }} Z_{2} R T_{2}}{P_{2}}-V_{R}$

172 where $P_{2}, Z_{2}$ and $T_{2}$ are the pressure, compressibility factor and temperature at equilibrium after

173 the valve is opened. All compressibility factors (Z) were determined using NIST's REFPROP

174 program (NIST, 2007). This program provides tables of the most accurate equations of state

175 available for all gases considered in this study, allowing the user to lookup compressibility

176 factors at any pressure and temperature for each gas.

177 Some authors have suggested a pressure dependent void volume of the reference cell,

178 owing to helium achieving a higher capacity to access finer and finer pores at higher pressures

179 (Ross and Bustin, 2007). Given these observations, we measured the reference cell volume over

180 a range of equilibrium pressures. However, we observed no variation in void volume with

181 pressure in our tests. An example of a typical void volume versus pressure measurement is

182 shown in Figure 2. This particular example is for the Eagle Ford shale sample.

183 Following void volume measurement with helium, the system was again vacuumed to

184 remove any residual helium that may have been trapped within the lines or sample particles. 
185 With the void volume of the reference cell determined, one can then perform expansions of an 186 adsorbing gas into the sample in the same manner already described. However, during the 187 expansion of an adsorbing gas from the reference cell to the sample, the pressure will decrease 188 due to both void volume filling as well as adsorption (adsorbed molecules are bound, and thus 189 have no kinetic energy and do not contribute to the gas phase pressure). Thus, the amount of 190 adsorption is the calculated as follows:

$191 \quad n_{\text {ads }}^{\text {excess }}=n_{\text {total }}-n_{\text {free }}$

192 where $n_{\text {total }}$ is the number of moles originally in the reference cell (the number of moles expected 193 to be in the system if no adsorption occurred), and $n_{\text {free }}$ is the number of molecules in the free 194 phase at equilibrium, calculated as:

$195 n_{\text {free }}=\frac{P_{2}\left(V_{R}+V_{S}\right)}{R T_{2} Z_{2}}$

196 where $V_{R}$ and $V_{S}$ are the reference and sample cell volumes, respectively. Following a

197 measurement at a single pressure, the valve separating the two chambers is closed, the reference

198 cell charged to a higher pressure and the process repeated until a full isotherm has been 199 characterized.

\subsection{Adsorption Data Analysis}

The procedure outlined above is for calculating what is termed excess adsorption (or

204 sometimes Gibbs adsorption), referring to the amount adsorbed in excess of that which would be 205 present if the adsorbed-phase volume were filled with bulk gas. In other words, as adsorption 206 occurs, the porosity occupied by the adsorbed phase that is no longer available to free gas must

207 be corrected for. Making this correction is called calculating the absolute, or total, amount of 208 adsorption. Failing to make this correction will result in an underprediction of the adsorbed 209 quantity.

210 Estimating absolute adsorption from excess adsorption data is a major challenge,

211 requiring knowledge of either the density or volume of the adsorbed phase. There have been very

212 few efforts at directly measuring the specific volume of gas molecules in the adsorbed state.

213 There are three common approaches for approximating this parameter. The first is to use the van 214 der Waals constant $b$ for the density (Dubinin, 1960). Equally common to this approach is to 
215 assume the adsorbate density to be that of the liquefied gas just below its boiling point (Tsai et

216 al., 1985). Finally, one might assume the density to be equal to that of the solidified gas. Perhaps

217 complicating matters, arguments have been made for employing a combination of two or more of

218 these assumptions depending on where along the adsorption isotherm the measurement is being

219 made (Menon, 1968).

220 In this work, we have elected to use the van Der Waals constant $b$ for the adsorbed phase

221 density, as first suggested by Dubinin, 1968. After making this assumption, the absolute

222 adsorption can be estimated as follows:

$223 \quad n_{\text {ads }}^{\text {absolute }}=\frac{n_{a d s}^{\text {excess }}}{1-\frac{\rho_{\text {gas }}}{\rho_{a d s}}}$

224 where $\rho_{\text {gas }}$ is the density of the gas phase and $\rho_{a d s}$ is the density of the adsorbed phase.

225 Once measurements have been complete and the appropriate corrections made, the data

226 can be fit to one of several isotherm models. The most common model used to describe an

227 adsorption isotherm was developed by Langmuir, 1916. The Langmuir isotherm describes a

228 progressively increasing surface occupancy as a function of pressure up until the entire surface

229 area is coated with a single layer of molecules and no further adsorption can occur. The entire

230 isotherm can be fit with a two-parameter equation:

$231 \quad V_{P}=\frac{V_{L} P}{P_{L}+P}$

232 where $V_{P}$ is the volume of adsorption at pressure $P, V_{L}$ is the Langmuir volume, representative of

233 total adsorption at infinite pressure, and $P_{L}$ is the Langmuir pressure, which is the pressure at

234 which half the Langmuir volume is adsorbed (Langmuir, 1916). Regardless of whether the

235 assumptions of the model are true, the Langmuir-shaped curve is so prolific and the model so

236 simple to apply that it is often selected in fitting experimental data as a matter of practicality. The

237 shapes of all adsorption isotherms presented in this paper are, in fact, well-fit by Langmuir

238 isotherms.

\subsection{Swelling}


As mentioned above, there have been no laboratory studies to date quantifying the

243 volumetric swelling strain associated with adsorption in gas shales. Such experiments are more

244 challenging in the context of shales for several reasons. First, measuring the swelling response to

245 adsorption needs to be performed on intact core plugs, requiring a significant amount of time.

246 Second, given that the amount of adsorption measured on gas shales is approximately an order of

247 magnitude less than what is observed in coal, one can expect at least an order of magnitude less

248 volumetric swelling strain. Finally, shales are an order of magnitude stiffer at the bulk scale

249 when compared to coals, further reducing the amount of swelling strain that one might expect to

250 observe with intact core plugs, thus making it very challenging to measure.

251 We measured volumetric swelling strain resulting from adsorption in a separate series of

252 experiments performed in a triaxial compression apparatus. Samples used in the swelling

253 experiments included carbon, illite and kaolinite. We elected to perform these measurements on

254 pure mineral particles as opposed to crushed or intact shale samples for two reasons. First, it

255 allowed us the advantage of overcoming the challenges associated with long equilibration times

256 and measuring very small strains, as discussed above. Second, measuring swelling of the

257 individual mineralogical constituents is a simpler way of answering the first order question of

258 whether or not swelling could be important in gas shales.

259 Measurements were made on the same set of clay and carbon samples, ground to the

260 same particle size and dried for the same period of time under the same conditions. A

261 combination of two jackets were used to isolate the sample and pore fluid from the confining

262 fluid, which included both copper as wells as a a Viton jacket. The thin copper jacket was chosen

263 for the inside in order to help prevent the pore fluid from exiting the sample by diffusion. In

264 addition, the copper provided a rigid cylinder within which to place the crushed material and

265 form the synthetic sample. A Viton jacket was chosen on the outside because of its compatibility

266 with our confining oil, as well as the integrity of the seal it formed against the stainless steel

267 coreholders.

268 The samples were cast inside of a 0.002 inch thick copper jacket that was cut from a sheet

269 and soldered at the seam to form a cylinder that was 1.0 inch in diameter and 2.0 inches in

270 length. The cylinder was first slid over a stainless steel coreholder. A 40 micron aperture circular

271 screen was then cut and placed inside of the cylinder to prevent particles from entering the

272 system plumbing. The copper was then filled with small aliquots of material and tamped until 
273 completion, and a second screen was placed on top of the sample. Heat shrinkable Viton tubing 274 was then slid over the outside of the copper, and the top coreholder was placed on the sample.

275 The tubing was then shrunk around the sample, and pre-positioned hose clamps were then 276 tightened around the Viton jacket. A pair of LVDT transducers (1 micron resolution) were 277 attached to the top and bottom coreholders to measure the change in distance between the 278 coreholders. The LVDT coil assembly is fixed within the top coreholder. The LVDT core is 279 attached to a rod with threads at the bottom, fixing it to the bottom coreholder. Finally, sample 280 deformation in the lateral direction was measured by a pair of spring-mounted strain-gauge 281 transducers (0.6 micron resolution; only one is drawn in Figure 3 for simplification) clamped to 282 the outside of the Viton jacket. The transducers were attached 90 degrees apart from each other 283 to measure the lateral deformation in two directions. All data was recorded digitally on a 284 personal computer equipped with a custom data acquisition system. See Figure 3 for a schematic 285 of the sample/jacket/coreholder configuration.

286 In order to form a compact sample from crushed material that behaved as elastically as 287 possible, all samples were stressed to a confining pressure of $30 \mathrm{MPa}$, which is approximately 288 twice as high the maximum confining pressure the sample would experience during the 289 experiment. The confining pressure was then cycled back and forth between 1 and $30 \mathrm{MPa}$ while 290 the strain was monitored to check for elasticity, which was typically achieved after about 15 291 cycles over a two hour period. A typical sequence of confining and pore pressure steps for a 292 single experiment is shown in Figure 4.

293 Following sample preparation, the sample was exposed to a series of escalating pore 294 pressures, maintaining a constant differential between the pore pressure and confining pressure 295 of $2 \mathrm{MPa}$ at each step (constant effective stress). Any swelling observed at each step was 296 recorded by the axial and lateral strain gauges attached to the sample setup. An obvious source of 297 error lies in the fact that the measured lateral displacement also includes deformation of the 298 Viton jacket. However, because the effective stress acting on the sample was kept constant, 299 jacket deformation was relatively invariant from one pore pressure step to the next, thus 300 impacting our measurements insignificantly. An example of a typical volumetric strain response 301 measured during an experiment is shown in Figure 5.

302 While we attempted to measure swelling at the same pore pressures at which adsorption 303 was measured, a perfect match was not achieved. However, all adsorption data was fit to an 
304 isotherm model, allowing for prediction of the adsorbed amount at any point along the curve.

305 This allowed us to compare swelling as a function of adsorbed volume, as opposed to just pore

306 pressure. However, we acknowledge that performing the swelling and adsorption experiments

307 separately could be a source of uncertainty in the results. An additional source of error is that

308 swelling was measured at room temperature (approximately $25^{\circ} \mathrm{C}$ ) whereas adsorption was

309 measured at $40^{\circ} \mathrm{C}$. Thus, we are likely to be slightly over predicting the swelling response from

310 adsorption. Despite these potential sources of error, we believe the data to be valuable toward

311 developing a phenomenological understanding of the linkage between swelling and adsorption in

312 minerals that comprise shales.

\section{RESULTS}

Methane and carbon dioxide adsorption isotherms were measured on samples from the

317 four shale reservoirs described above. All data was successfully fit to Langmuir adsorption

318 isotherms. Fitted adsorption parameters are shown in Table 2, and plots of absolute adsorption

319 are shown in Figure 6. For all samples, $\mathrm{CO}_{2}$ exhibited a greater capacity for adsorption relative to

$320 \mathrm{CH}_{4}$ (about 2 times greater in the Barnett and Marcellus samples, and 3 times greater in the

321 Montney and Eagle Ford samples). Both $\mathrm{CH}_{4}$ and $\mathrm{CO}_{2}$ adsorption capacities varied greatly

322 between samples as well, with the Barnett and Montney samples adsorbing considerably more

323 than the Marcellus and Eagle Ford samples (about 2-6 times more $\mathrm{CH}_{4}$ and $\mathrm{CO}_{2}$ adsorption,

324 respectively). A look at the mineralogical differences between these samples indicates that

325 composition was likely a major controlling factor of these differences, but not the only one. The

326 Barnett sample had the highest amount of TOC (5.3\%) and also the largest adsorption capacity.

327 Perhaps the most surprising sample was the Montney, which had a modest amount of TOC (2\%)

328 and clay (23.7\%), but demonstrated a fairly high capacity for adsorption. The Eagle Ford sample

329 was the least adsorptive of all samples, even though it had slightly more TOC than the Marcellus

330 (1.8 vs. 1.2\%). If the clay fraction contributes to total adsorption capacity, the difference might

331 be explained by the Marcellus sample having a high clay fraction of $41.3 \%$ while the Eagle Ford

332 was mostly carbonate and had just $4.9 \%$ clay. However, clay adsorption is just one possible

333 explanation for the observed differences in adsorption capacity. Differences in the maturity of

334 the organic matter and microstructure of the rock may also play a significant role. In general, the 
greater the maturity of the organic matter the greater the surface area, and thus the greater the adsorptive capacity. The Eagle Ford sample was the most thermally mature but the least adsorptive, perhaps further supporting the hypothesis that other minerals (such as clays) play an important role in adsorption.

Methane and carbon dioxide adsorption isotherms were measured for samples of illite, kaolinite and carbon as well. Again, we were able to successfully fit all data using the Langmuir model. Fitted adsorption parameters are shown in Table 2, and plots of absolute adsorption are shown in Figure 7. Similar to the shale adsorption isotherms, $\mathrm{CO}_{2}$ demonstrated a greater capacity for adsorption relative to $\mathrm{CH}_{4}$ (at 1000 psi, about 1.5 times greater in illite, 4 times greater in kaolinite, and 3 times greater in carbon). The magnitude of both $\mathrm{CH}_{4}$ and $\mathrm{CO}_{2}$ adsorption in all cases is quite significant and beyond what we would expect given the magnitude of adsorption we have measured in our shale samples. To illustrate this point, we calculated hypothetical $\mathrm{CH}_{4}$ Langmuir volumes for each shale sample, assuming adsorption in shales to be equal to the sum of adsorption by the individual minerals which comprise it. For simplicity, we will also assume all clay to be illite (a close look at the clay XRD data show the clay fraction to be dominated by illite) and that no other minerals present within the samples are capable of adsorption. With these assumptions, one would calculate Langmuir volumes for the Barnett, Eagle Ford, Marcellus and Montney shale samples to be about 4.5 times, 8 times, 4.6 times and 1.9 times what was actually measured, respectively (see Table 3 for details of calculation). Similar results have been found by other authors (Schettler et al., 1991; Lu et al., 1995). These results are considered further in the discussion section.

In addition to adsorption, the volumetric swelling strain associated with the adsorption of $\mathrm{CH}_{4}$ and $\mathrm{CO}_{2}$ was measured for the pure mineral samples. The volumetric swelling strain is 358 plotted as a function of the amount of adsorption on a linear scale in Figure 8a, and on a log-log scale in Figure 8b. On a linear scale, carbon data must be plotted separately as the amount of

360 adsorption and swelling far exceeds that of illite and kaolinite. On a log-log scale, all data is able 361 to fit on the same graph, and the relative magnitude of adsorption and swelling by the carbon 362 sample is more easily compared to the clay.

363 The magnitude of the swelling strain measured varied from $\sim 5 \times 10^{-5}$ to $\sim 5 \times 10^{-3}$, or 364 approximately two orders of magnitude. The amount of adsorption causing this swelling strain, 365 varied from about $10^{-1}$ to $10^{-4}$, or nearly 3 orders of magnitude. Viewing the data plotted on a 
linear scale, we observe both clay and carbon to swell in amount that is roughly linearly

367 proportional to the amount of adsorption. In addition, we observe a similar amount of swelling

368 for a given amount of adsorption on the same sample regardless of whether $\mathrm{CH}_{4}$ or $\mathrm{CO}_{2}$ is the

369 adsorbing gas. However, for a given amount of adsorption, the magnitude of swelling observed

370 for each sample was quite different. We attributed this to the difference in the stiffness between

371 samples. While the elastic moduli were not measured, we assume differences in bulk sample

372 stiffness to correlate roughly with the differences in mineral elastic moduli, which are tabulated

373 in Table 3. This data supports the notion that for a given amount of adsorption, the stiffer the

374 mineral, the less the amount of swelling strain.

\section{DISCUSSION}

\subsection{Adsorption}

The methane adsorption isotherm we measured on our Barnett shale sample is very similar in both shape and magnitude to those found in the literature. Kang et al. (2010) measured methane adsorption on two Barnett shales at $\mathrm{CH}_{4}$ pressures in the range of 1000-3000 psi. They measured an adsorption capacity of approximately 40-50 scf/ton at $1000 \mathrm{psi}$. Montgomery et al. (2005) presented Barnett methane adsorption capacities from 40-75 scf/ton at the same pressure. Our measurement of $\sim 50 \mathrm{SCF} /$ ton at 1000 psi lies within the same range as both of these studies. We are not aware of any adsorption isotherms for Montney, Marcellus or Eagle Ford shale samples within the literature at the time of this writing.

To date there have only been two published papers on $\mathrm{CO}_{2}$ adsorption in gas shales.

Nuttall et al. (2005) measured $\mathrm{CH}_{4}$ and $\mathrm{CO}_{2}$ adsorption on Devonian black-shale samples from Kentucky. They found Langmuir-like $\mathrm{CO}_{2}$ adsorption that was approximately 5 times greater than the amount of $\mathrm{CH}_{4}$ adsorption. In the same study as their $\mathrm{CH}_{4}$ measurements, Kang et al. (2010) measured $\mathrm{CO}_{2}$ adsorption on the same two Barnett shale samples. Their measurements were taken at $\mathrm{CO}_{2}$ pressures from 2000-4000 psi, which is higher than the pressure range over which our measurements were taken (50-800 psi). Moreover, their measurements were made at an unspecified temperature. Nevertheless, they extrapolate their isotherms to a $\mathrm{CO}_{2}$ adsorption capacity of $\sim 140 \mathrm{scf} / \mathrm{ton}$ at $500 \mathrm{psi}$ in one sample, and $\sim 250 \mathrm{scf} / \mathrm{ton}$ at $500 \mathrm{psi}$ in the other. This is approximately 5 times and 10 times greater than the $\mathrm{CH}_{4}$ adsorption they measured in the two samples at that pressure, respectively. The $\mathrm{CO}_{2}$ adsorption capacity of our Barnett sample was 
about $75 \mathrm{scf} /$ ton at $500 \mathrm{psi}$, which is about $2 \mathrm{x}$ the amount of methane adsorption measured at that 398 pressure.

399 All experimental data was corrected for the volume of the adsorbed phase as previously 400 described. An example of the data both before and after the correction is shown in Figure 9 for 401 the Barnett shale sample. For this particular sample, failing to account for the volume occupied 402 by the adsorbed phase results in underestimating the quantity of adsorbed gas and total gas 403 storage by about $10 \%$.

404 Of particular interest is the question of how important the adsorbed phase is in terms of 405 producible gas in place. In Figure 10, we show production of free, adsorbed and total methane as 406 a function of pressure for the four shale samples tested in this study. All estimates were made at $40740^{\circ} \mathrm{C}$ (experimental conditions) and assuming equal porosity (8\%) and water saturation (25\% of 408 the pore volume occupied by water) for the sake of comparison. These assumptions result in an 409 equivalent free gas production from all samples, allowing us to focus on the impact of the 410 different adsorption isotherms between samples. By looking at the height of the total gas 411 production at zero pressure, we see that the higher the adsorptive capacity (higher the Langmuir 412 volume) the greater the quantity of adsorbed (and therefore total) gas produced. The most 413 important observation made clear by the figure is that, for rocks in which these isotherms are 414 representative, adsorption would be relatively unimportant in terms of producible gas in place. 415 However, we are careful not to generalize this result, and acknowledge the high degree of 416 heterogeneity that exists between different formations, and even between different lithologies 417 within the same formation.

418 Our results also suggest the importance of isotherm shape, which is evident by comparing 419 the Barnett and Montney samples. Despite having a higher capacity for adsorption (higher 420 Langmuir volume), close inspection of the isotherm at 1000 psi shows us that the Montney 421 sample would have produced slightly more adsorbed (and therefore total) gas per ton of rock. 422 The adsorption isotherm for the Montney has a relatively high Langmuir pressure, allowing for 423 greater desorption at higher pressures. Given that a large portion of the reservoir may never 424 experience pressures lower than 1000 psi, it may be fair to say that isotherm shape is as 425 important as total adsorption capacity when answering the question of how important adsorbed 426 gas will be to overall production. 
Our adsorption measurements on clay minerals showed a much larger than expected 428 amount of adsorption if one were to assume the total adsorptive capacity of a rock to be roughly 429 equal to the sum of the capacities of its mineral constituents. Similar results have been found by 430 other authors, as described in the introduction (Schettler et al., 1991; Lu et al., 1995; Ross and 431 Bustin, 2008). One potentially important factor is compaction and the microstructural difference 432 between the ground clay minerals used in our experiments and their in-situ structure. Another 433 important factor is likely water. We suspect that water adsorption plays an important role in 434 regulating the amount of free surface area available for other molecules to adsorb. Passey et al.

435 (2010) reported that much of the water present in shale gas systems is likely adsorbed on and 436 associated with the surface of clay minerals. Recall that in preparing our shale and clay samples 437 for adsorption, they were dried in a vacuum oven for an extended period of time. Thus, clay 438 surfaces that would be largely occupied by water in situ were likely available for adsorption 439 during our experiments. This would impact both our pure clay and shale adsorption

440 measurements, resulting in an overestimation of methane (and carbon dioxide) adsorption in both 441 cases. Water adsorption and the impact it might have on $\mathrm{CH}_{4}$ and $\mathrm{CO}_{2}$ adsorption remains a 442 major experimental challenge to be overcome.

443 Another potential factor impacting our adsorption measurements on clay minerals is the 444 difference between

\subsection{Swelling}

Another challenging issue is the relationship between stress, strain and

449 adsorption/desorption. We have successfully measured the volumetric swelling strain associated 450 with the adsorption of $\mathrm{CH}_{4}$ and $\mathrm{CO}_{2}$ on carbon and clay samples to be on the order of $10^{-5}$ to $10^{-}$

$451{ }^{3}$. In order to establish that swelling from adsorption is the cause of the observed volumetric 452 strain, the swelling response to helium as a pore fluid was measured as well. Helium is an inert 453 gas, and therefore non-adsorbing. An example of volumetric strain versus pressure is shown in 454 Figure 11, demonstrating that swelling strain is not observed in the case of helium. 455 Rather than examine adsorption as a function of pressure, it is more useful to evaluate 456 swelling as a function of the amount of adsorption. The magnitude of the swelling strain is 457 clearly dependent on the quantity of adsorption, as shown in Figure 8. Moreover, there seems to 
be a material dependence. For a given amount of adsorption, the magnitude of the associated strain varies by approximately one order of magnitude. We hypothesize that this variance might be attributed to a difference in mineral stiffness.

It is difficult to speculate on the implications of the swelling strains we have measured.

462 The strains we report are observed at the bulk/sample scale, and how this translates to strain at 463 the pore scale, where adsorption and transport are occurring, is unknown. Kowalczyk et al.

464 (2010) modeled adsorption-induced deformation on microporous carbons and made several 465 interesting observations. They calculated the stresses resulting from adsorption/condensation in 466 micropores to be on the order of $1000 \mathrm{GPa}$, and predicted strains at the bulk scale on the order of $46710^{-3}$ caused entirely by deformation at the micropore scale. Future studies might focus on 468 developing fully coupled simulations of adsorption, deformation and transport at this scale to better understand how this might impact production in shales.

\section{CONCLUSIONS}

We measured the adsorptive capacity of four gas shale samples as well as samples of 474 pure carbon, illite and kaolinite. The Barnett shale sample had the highest TOC and adsorbed the 475 most, followed by the Montney, Marcellus and Eagle Ford sample. The carbon sample adsorbed an extremely large amount, however, the extent to which it can be thought of as an analogue to the organic content of shales is unknown. Illite and kaolinite also exhibited a relatively high capacity for adsorption. Similar to other studies, we find difficulty in describing shale adsorption isotherms as being the sum of the isotherms of its mineral constituents.

From an enhanced recovery or the $\mathrm{CO}_{2}$ storage perspective, our results are quite favorable. We have shown that $\mathrm{CO}_{2}$ has a higher capacity for adsorption in four different shale samples as well as the major mineral constituents shale is comprised of. Follow up studies might investigate the preferential adsorption of $\mathrm{CO}_{2}$ in a mixed gas setting.

It has been suggested that the desorption of methane might be partially responsible for the relatively long and flat production tails that have been observed in some shale reservoirs (Valko and Lee, 2010). The results presented in this paper demonstrate the increased importance of adsorption to production as pressure decreases. However, the magnitude of adsorption in the four shale samples examined in this paper was relatively small, and for these rocks, the adsorbed 
489 phase would be relatively unimportant in terms of producible gas in place. Other formations, or 490 even other lithologies within the same formations, may yield entirely different results. Moreover, 491 comparing adsorption isotherms for the Barnett and Montney samples underscores the 492 importance of considering not just the adsorption capacity of the rock, but the shape of the 493 adsorption isotherm as well.

494 Finally, we demonstrated the swelling nature of carbon and clay minerals in response to 495 adsorption. Future experiments and simulations are required to better understand the relationship 496 between adsorption, swelling and transport in gas shales, and how adsorption-induced 497 deformation might impact production.

498 
500 Figure 1. Schematic of system used for adsorption measurements. Both reference and sample cells are placed inside of a temperature controlled oil bath for stability, which was set to $40^{\circ} \mathrm{C}$ in all experiments. The volumes of both cells are adjustable using aluminum spacers to accommodate varying sample sizes without sacrificing measurement stability.

Figure 2. Void volume versus pressure for the Eagle Ford sample. Note that no dependency of void volume on pressure was observed. Void volume measurement scattered about a mean of $14.956 \mathrm{ml}$, with as standard deviation of $0.0045 \mathrm{ml}$.

Figure 3. Schematic of sample setup for swelling experiments. A side view of the entire core holder and sample assembly is shown in Figure 3a. A top view of just the jacket and lateral strain gauge configuration is illustrated in Figure $3 b$ (only one of the two lateral gauges is shown for simplicity). The sample was loaded inside of a soldered copper sleeve, encased in heat-shrink Viton tubing to isolate the sample from the confining fluid. Core holders are shown on either end, with axial and lateral strain gauges affixed to the setup as well.

Figure 4. A typical sequence of confining and pore pressure steps for a single experiment. In order to form a compact sample from crushed material that behaved as elastically as possible, the confining pressure was cycled back and forth between 1 and $30 \mathrm{MPa}$ while the strain was monitored to check for elasticity. Following this sequence, swelling is measured as a series of escalating pore pressures while maintaining a constant effective stress on the sample.

Figure 5. Volumetric strain signal versus time during an activated carbon swelling experiment with methane as the test gas. Positive strain indicates swelling in this convention.

Figure 6. Methane and carbon dioxide adsorption isotherms on samples from the Barnett, Marcellus, Eagle Ford and Montney shale reservoirs. Points indicate pressures where data was collected, and lines indicate modeled isotherms fit using parameters shown in Table 2. All axes are scaled the same for ease of comparison between samples. For all samples, $\mathrm{CO}_{2}$ exhibited a greater capacity for adsorption relative to $\mathrm{CH}_{4}\left(\mathrm{CO}_{2}\right.$ about $2 \mathrm{x}$ greater in the Barnett and Marcellus, and 3x greater in the Montney and Eagle Ford samples). The Barnett sample adsorbed the most, followed by the Montney, Marcellus and finally the Eagle Ford sample.

Figure 7. Methane and carbon dioxide adsorption on samples of pure illite, kaolinite and activated carbon. Note that in the case of activated carbon, the scale is multiplied by a factor of 10,000 .

Figure 8. (a) Linear scale: volumetric swelling strain as a function of the amount of adsorbed methane (circles) and carbon dioxide (triangles). The data suggests an approximately linear relationship between the observed swelling strain and the amount of adsorption. Moreover, for a given amount of adsorption, the stiffer the mineral, the less the amount of observed swelling strain. (b) Log-log scale: volumetric swelling volumetric swelling strain as a function of the amount of adsorbed methane (circles) and carbon dioxide (triangles). Scaled accordingly, all data is able to fit on the same graph, and the relative magnitude of adsorption and swelling by the carbon sample is more easily compared to the clay. 
Figure 9. Left: Barnett excess and total adsorption. Total adsorption calculation required correcting for the volume occupied by the adsorbed phase, as described in the methodology section. Right: Free $\mathrm{CH}_{4}$, adsorbed $\mathrm{CH}_{4}$ and total $\mathrm{CH}_{4}$ storage of the Barnett sample as a function of pressure. Solid lines indicated data that has been corrected for the volume of the adsorbed phase, while dashed lines indicate the same data without the correction. If the correction is not made, both the adsorbed and total storage capacity of the rock is underestimated, and the free gas capacity is slightly overestimated due to the pore volume occupied by the adsorbed phase.

Figure 10. Production of free, adsorbed and total methane as a function of pressure. All estimates were made at $40^{\circ} \mathrm{C}$ and assuming equal porosity and water saturation for ease of comparison.

Figure 11. An example of volumetric strain versus pressure for the activated carbon sample. Note that no swelling is observed when helium is the pore fluid, as helium is an inert (and therefore non-adsorbing) gas.

Table 1. Sample mineralogy and Rock Eval Pyrolisis data. Pyrolisis data indicates that the Eagle Ford 127 sample to lies within the dry gas window, while the Barnett and Marcellus samples are less mature and slightly more oil-prone.

Table 2. Langmuir isotherm parameters fit to experimental data. The Barnett sample, which had the highest amount of TOC and a high clay fraction, adsorbed the most out of the gas shale samples. The Montney sample exhibited a fairly high capacity for adsorption despite being comprised of a relatively modest amount of TOC and clay. The Marcellus sample had the lowest TOC content but very high clay content, and adsorbed slightly more than the Eagle Ford. The Eagle Ford sample, which had very little clay and was dominated by carbonate, adsorbed the least.

Table 3. Hypothetical $\mathrm{CH}_{4}$ Langmuir volume calculations for shale samples studied in this work. The results demonstrate that the magnitude of adsorption is drastically over-predicted if one assumes adsorption in shales to be equal to the sum of the adsorption by its mineralogical constituents. The calculated Langmuir volumes are 4.5 times, 8 times, 4.6 times and 1.9 times the measured Langmuir volumes in the Barnett, Eagle Ford, Marcellus and Montney samples, respectively. 


\section{ACKNOWLEDGEMENTS}

583 We gratefully acknowledge financial support from the Department of Energy (Grant DE-FE-

584 0004731), BP, the Research Partnership to Secure Energy for America (RPSEA), and the

585 Stanford Rock and Borehole Geophysics consortium (SRB). In addition, we would like to thank

586 ConocoPhillips and BP for providing samples for us to work with. 


\section{REFERENCES}

Ambrose, R., Hartman, R., diaz campos, M., Akkutlu, I. Y., \& Sondergeld, C. (2010, February). New pore-scale considerations for shale gas in place calculations. In SPE Unconventional Gas Conference.

Angus, S., Armstrong, B., \& De Reuck, K. M. (1978). International thermodynamic tables of the fluid state. 5. Methane.

Bustin, R.M., Bustin, A.M.M., Cui, A., Ross, D., and Pathi, V.M., 2008, Impact of shale properties on pore Structure and storage characteristics: SPE Shale Gas Production Conference.

Chalmers, G. R., \& Bustin, R. M. (2008). Lower Cretaceous gas shales in northeastern British

601 Columbia, Part I: geological controls on methane sorption capacity. Bulletin of Canadian

602 Petroleum Geology, 56(1), 1-21.

603

604

605

606

607
Cui, X., Bustin, A. M. M., and Bustin, R. M., 2009, Measurements of gas permeability and diffusivity of tight reservoir rocks: different approaches and their applications: Geofluids, v. 9, p. 208-223.

Dubinin, M. M. (1960). The potential theory of adsorption of gases and vapors for adsorbents with energetically nonuniform surfaces. Chemical Reviews, 60(2), 235-241.

Hol, Sander, Colin J. Peach, and Christopher J. Spiers. "Applied stress reduces the $\mathrm{CO}_{2}$ sorption capacity of coal." International Journal of Coal Geology 85.1 (2011): 128-142.

Lin et al, 2010

Kang, S. M., Fathi, E., Ambrose, R. J., Akkutlu, I. Y., \& Sigal, R. F. (2010). Carbon dioxide storage capacity of organic-rich shales. SPE, 134583, 1-17.

Kleinrahm, R., \& Wagner, W. (1986). Measurement and correlation of the equilibrium liquid and vapour densities and the vapour pressure along the coexistence curve of methane. The Journal of Chemical Thermodynamics, 18(8), 739-760.

Kowalczyk, P., Furmaniak, S., Gauden, P. A., and Terzyk, A. P., 2010, Carbon dioxide adsorption-induced deformation of microporous carbons: The Journal of Physical Chemistry C, v. 114, p. $5126-5133$.

Langmuir, I. (1916). The constitution and fundamental properties of solids and liquids: Part I, Solids. Journal of the American Chemical Society, 38(11), 2221-2295.

Loucks, R. G., Reed, R. M., Ruppel, S. C., \& Jarvie, D. M. (2009). Morphology, genesis, and distribution of nanometer-scale pores in siliceous mudstones of the Mississippian Barnett Shale. Journal of Sedimentary Research, 79(12), 848-861. 
Lu, X. C., Li, F. C., \& Watson, A. T. (1995). Adsorption measurements in Devonian shales.

634 Fuel, 74(4), 599-603.

Menon, P. G. "Adsorption at high pressures." Chemical Reviews 68.3 (1968): 277-294.

NIST, 2007, NIST Reference Fluid Thermodynamic and Transport Properties Database (REFPROP): Version 9.0.

Nuttall, B. C., Eble, C. F., Drahovzal, J. A., \& Bustin, R. M. (2005). Analysis of Devonian black shales in Kentucky for potential carbon dioxide sequestration and enhanced natural gas production. Report Kentucky Geological Survey/University of Kentucky (DE-FC26-02NT41442).

Passey, Q., Bohacs, K., Esch, W., Klimentidis, R., \& Sinha, S. (2010, June). From oil-prone source rock to gas-producing shale reservoir-geologic and petrophysical characterization of unconventional shale gas reservoirs. In International Oil and Gas Conference and Exhibition in China.

Peters, K. E., \& Moldowan, J. M. (1993). The biomarker guide: interpreting molecular fossils in petroleum and ancient sediments.

Ross, Daniel JK, and R. Marc Bustin. "Impact of mass balance calculations on adsorption capacities in microporous shale gas reservoirs." Fuel 86.17 (2007): 2696-2706.

Ross, D. J., \& Marc Bustin, R. (2009). The importance of shale composition and pore structure upon gas storage potential of shale gas reservoirs. Marine and Petroleum Geology, 26(6), 916927.

Schettler, P. D., Parmely, C. R., \& Juniata, C. (1991). Contributions to total storage capacity in Devonian shales. SPE paper, 23422.

Silva, S. R. P. (Ed.). (2003). Properties of amorphous carbon (No. 29). Iet.

Sondergeld, C.H., Ambrose, R.J., Rai, C.S., and Moncrieff, J., 2010, Micro-structural studies of gas shales: SPE Unconventional Gas Conference.

Tsai, M. C., et al. "Adsorption of gas mixture on activated carbon." Carbon 23.2 (1985): 167173.

Valko, P., \& Lee, W. (2010, September). A better way to forecast production from unconventional gas wells. In SPE Annual Technical Conference and Exhibition.

Wang, F.P., and Reed, R.M., 2009, Pore networks and fluid flow in gas shales: SPE Annual Technical Conference and Exhibition.

Wang, Z., Wang, H., \& Cates, M. E. (2001). Effective elastic properties of solid clays. Geophysics, 66(2), 428-440. 
680 Yang, Y., and Aplin, A. C., 2007, Permeability and petrophysical properties of 30 natural 681 mudstones: Journal of Geophysical Research, v. 112. 


\begin{tabular}{|c|c|c|c|c|}
\hline & Barnett 31 & Eagle Ford 127 & Marcellus & Montney \\
\hline Depth (ft) & $8,640.8$ & $12,771.35$ & 6,300 & $7,614.52$ \\
\hline Depth (m) & $2,633.7$ & $3,893.70$ & $1,920.73$ & $2,321.50$ \\
\hline Initial Mass (g) & 41.32 & 46.46 & 34.42 & 38.33 \\
\hline Mass After Drying (g) & 41.19 & 46.35 & 34.34 & 38.22 \\
\hline Water by Mass \% & 0.31 & 0.24 & 0.22 & 0.28 \\
\hline $\operatorname{TOC}(\%)$ & 5.3 & 1.8 & 1.2 & 2.0 \\
\hline Quartz (\%) & 51.3 & 7.0 & 38.0 & 42.3 \\
\hline Plagioclase/Feldspar (\%) & 4.0 & 4.0 & 6.0 & 11.9 \\
\hline Calcite (\%) & 0.0 & 80.0 & 1.0 & 8.1 \\
\hline Dolomite (\%) & 0.4 & 1.0 & 1.0 & 9.9 \\
\hline Pyrite (\%) & 1.7 & 1.0 & 1.0 & 3.5 \\
\hline Apatite (\%) & 0.0 & 2.0 & 1.0 & 0.0 \\
\hline Total Clay (\%) & 37.4 & 5.0 & 52.0 & 24.1 \\
\hline S1 (mg HC/g rock) & 4.4 & 2.88 & 2.06 & N/A \\
\hline S2 (mg HC/g rock) & 6.1 & 1.36 & 5.15 & N/A \\
\hline S3 (mg HC/g rock) & 0.3 & 0.54 & 0.31 & N/A \\
\hline $\operatorname{Tmax}\left({ }^{\circ} \mathbf{C}\right)$ & 452 & 466 & 369 & N/A \\
\hline HI (mg HC/g TOC) & 115 & 75 & 439 & N/A \\
\hline OI (mg CO2/g TOC) & 6 & 30 & 26 & N/A \\
\hline
\end{tabular}




\section{Table_2}

\begin{tabular}{|c|c|c|c|c|c|c|c|}
\hline & Barnett 31 & Eagle Ford 127 & Marcellus & Montney & Illite & Kaolinite & Carbon \\
\hline TOC (\%) & 5.3 & 1.8 & 1.2 & 2.0 & 0 & 0 & 100 \\
\hline Clay (\%) & 37.4 & 4.9 & 51.4 & 23.7 & 100 & 100 & 0 \\
\hline \multicolumn{8}{|l|}{ Methane } \\
\hline PL (psia) & 580.5 & 694.7 & 556.2 & 1283.0 & 599.6 & 701.8 & 452.4 \\
\hline VL (scf/ton) & 74.4 & 12.7 & 28.3 & 54.3 & 133.7 & 31.7 & $5,369.6$ \\
\hline \multicolumn{8}{|l|}{ Carbon Dioxide } \\
\hline PL (psia) & 475.1 & 409.6 & 263.2 & 456.0 & 118.8 & 358.8 & 676.2 \\
\hline VL (scf/ton) & 147.4 & 33.1 & 63.7 & 153.0 & 161.2 & 114.4 & $26,001.9$ \\
\hline
\end{tabular}


Table_3

\begin{tabular}{|c|c|c|c|c|c|c|c|c|c|c|c|c|c|c|}
\hline & \multicolumn{5}{|c|}{ Adsorption from Carbon } & \multirow[t]{2}{*}{+} & \multicolumn{5}{|c|}{ Adsorption from Clay } & \multirow[t]{2}{*}{$=$} & \multicolumn{2}{|c|}{ Total Adsorption } \\
\hline & TOC (\%) & & $\mathrm{VL}$ (scef/ton) & & Vads (sc/ton) & & Clay (\%) & & $\mathbf{V L}$ (sce/ton) & & Vads (scf/ton) & & Calculated (sce/ton) & Actual (scf/ton) \\
\hline Barnett 31 & 5.3 & $\mathrm{x}$ & 5369.6 & $=$ & 284.3 & & 37.4 & $\mathrm{x}$ & 133.7 & $=$ & 50.0 & & 334.3 & 74.4 \\
\hline Eagle Ford 127 & 1.8 & $\mathrm{x}$ & 5369.6 & $=$ & 95.5 & & 4.9 & $\mathrm{x}$ & 133.7 & $=$ & 6.6 & & 102.0 & 12.7 \\
\hline Marcellus & 1.2 & $\mathrm{x}$ & 5369.6 & $=$ & 62.1 & & 51.4 & $\mathrm{x}$ & 133.7 & $=$ & 68.7 & & 130.8 & 28.3 \\
\hline Montney & 2.0 & $\mathrm{x}$ & 5369.6 & $=$ & 107.4 & & 23.7 & $\mathrm{x}$ & 133.7 & $=$ & 31.7 & & 139.1 & 73.3 \\
\hline
\end{tabular}




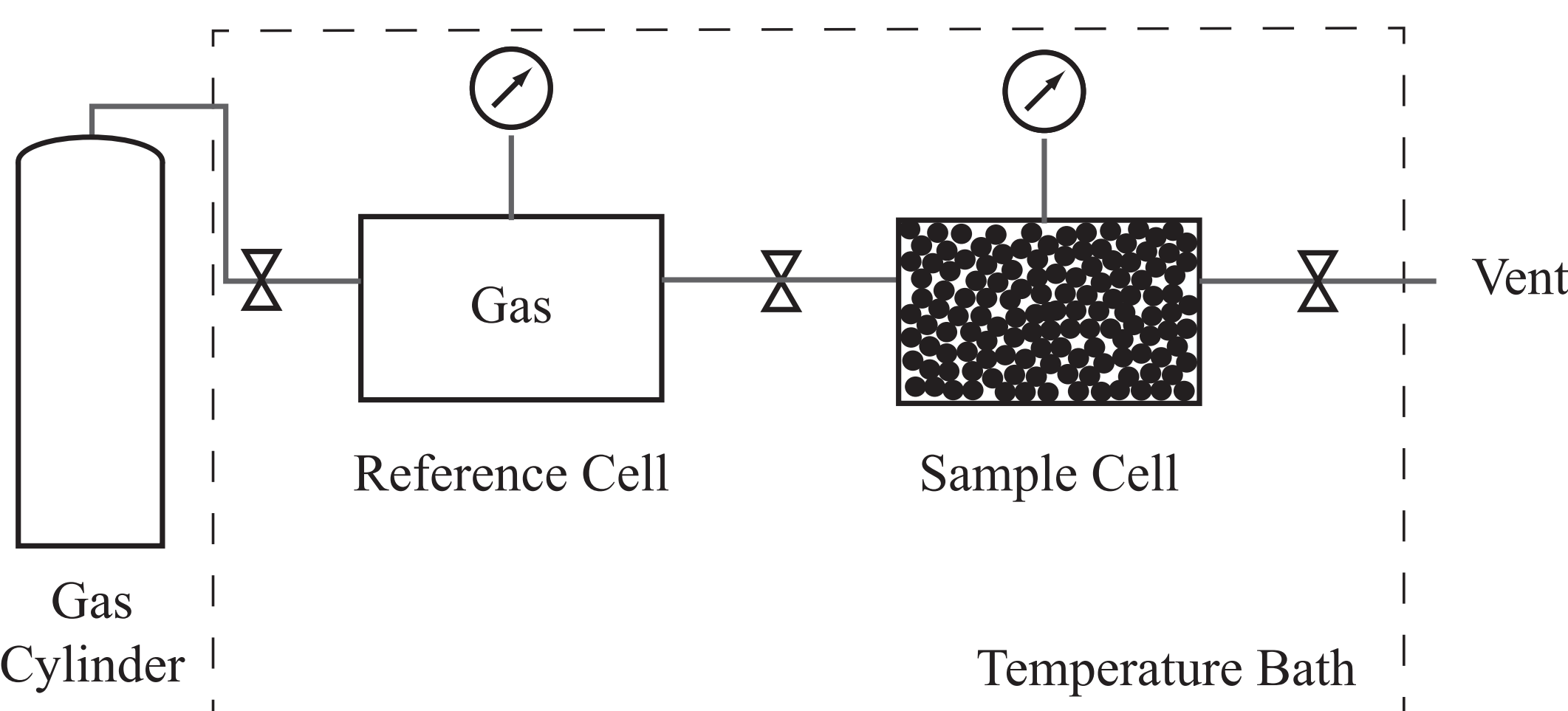


Figure_2

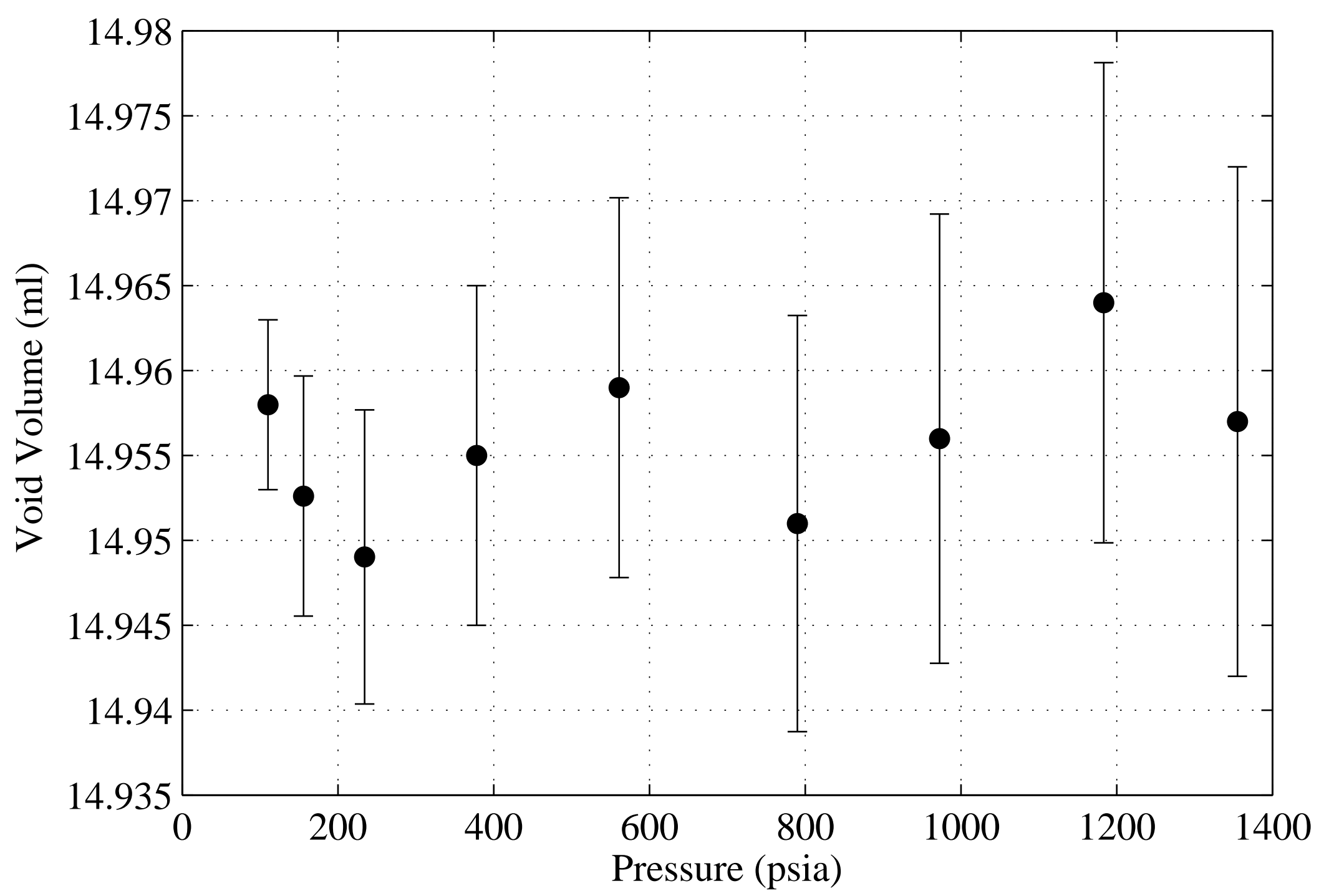


Figure_6
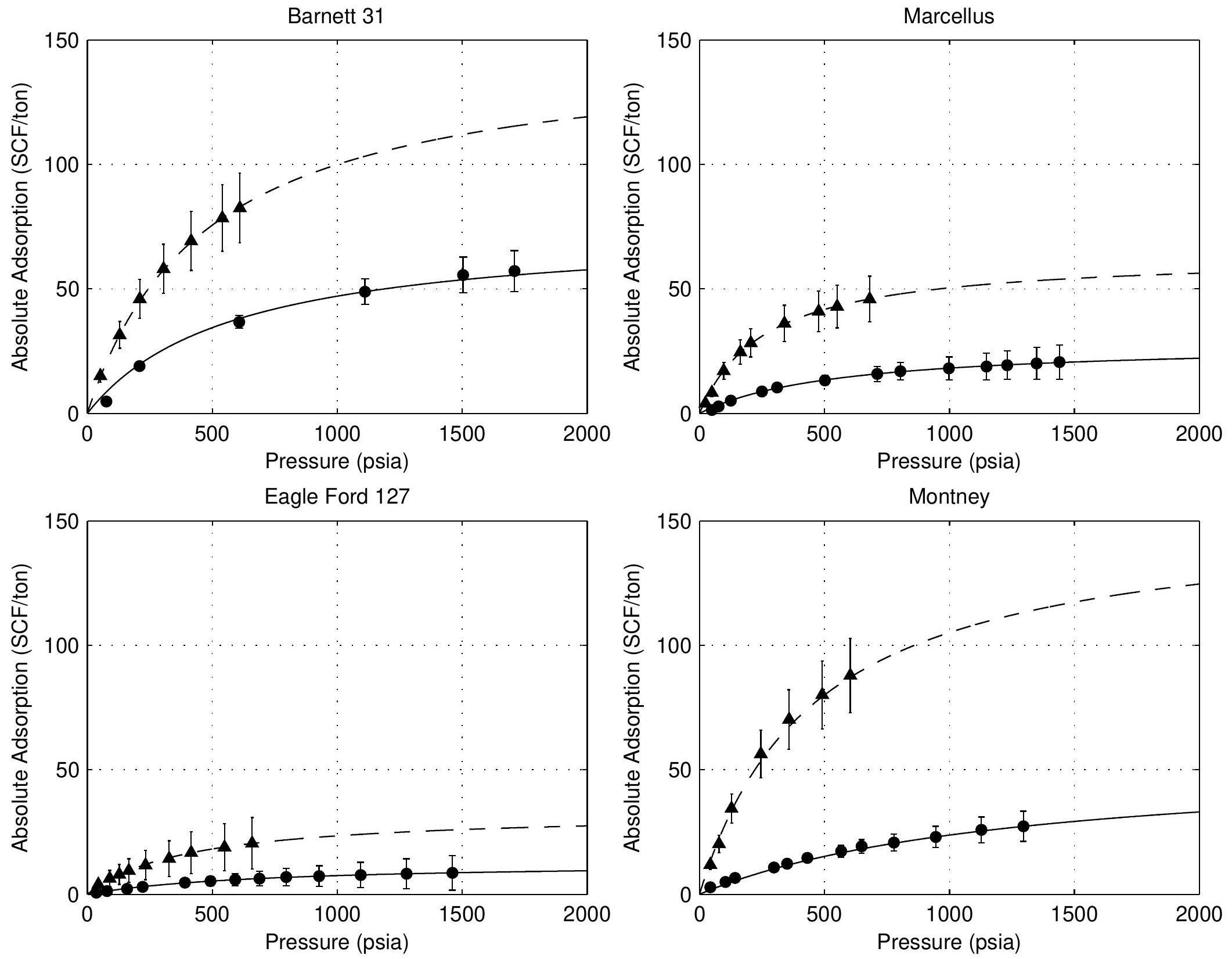

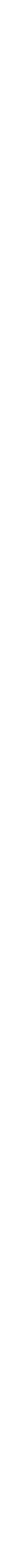
Figure_9
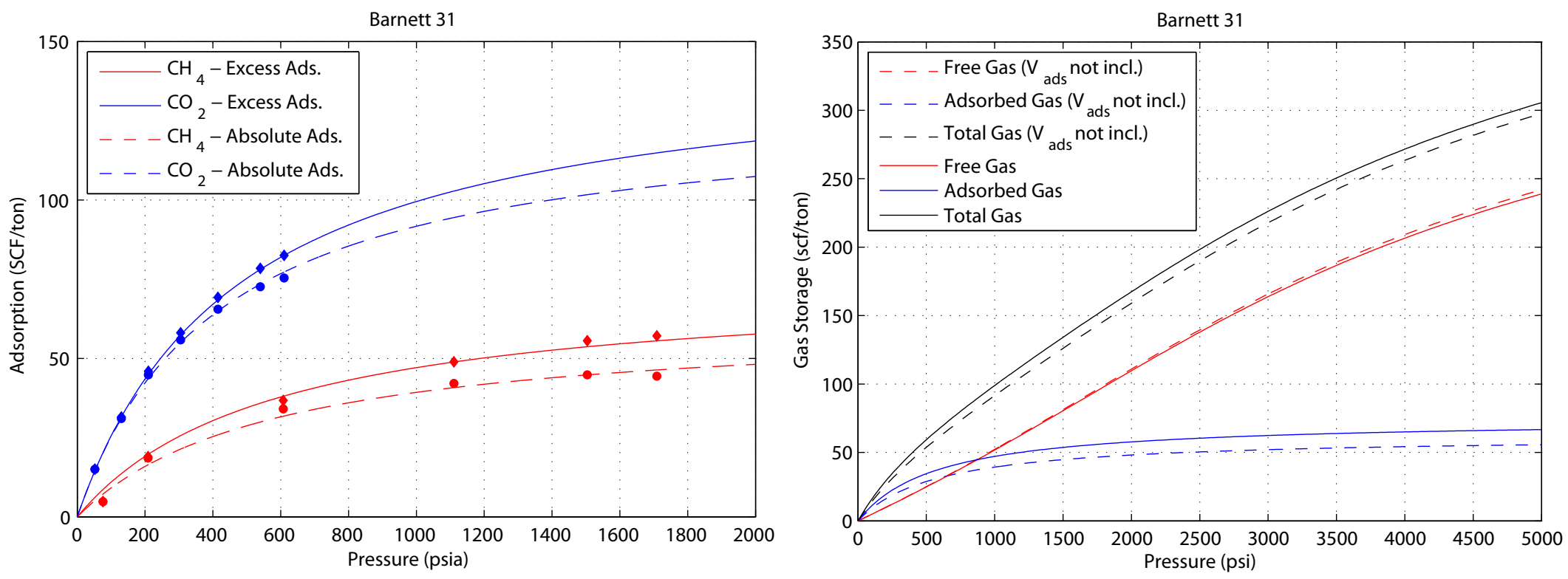
Barnett 31

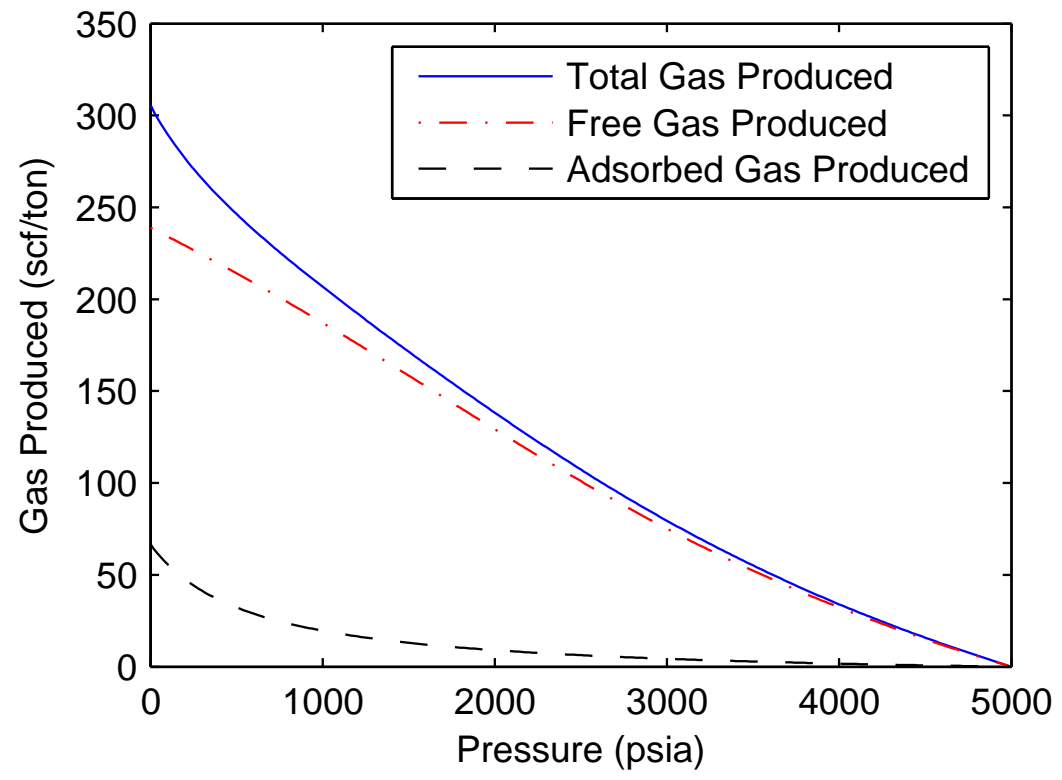

Eagle Ford 127

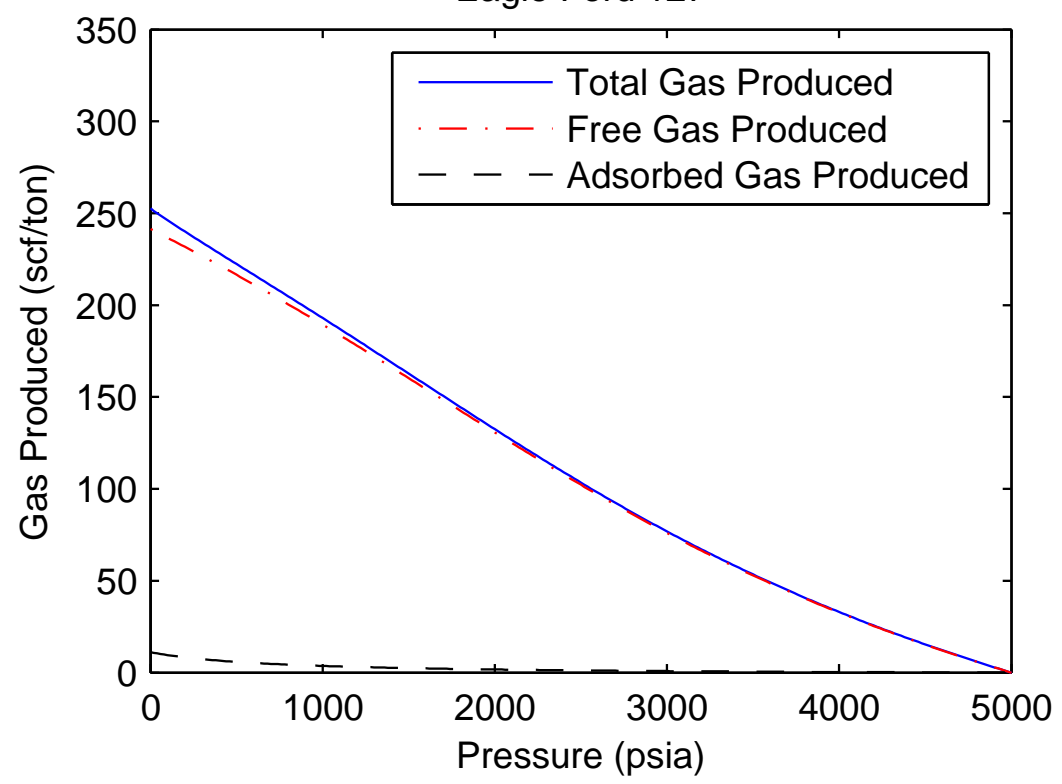

Marcellus

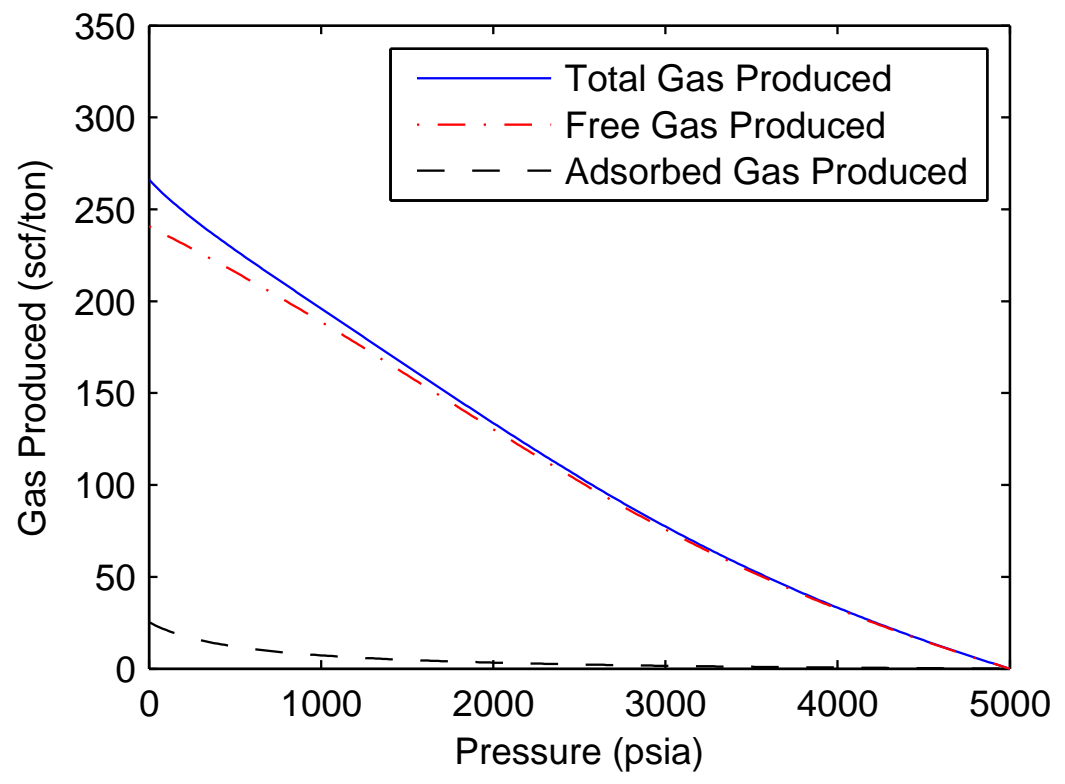

Montney

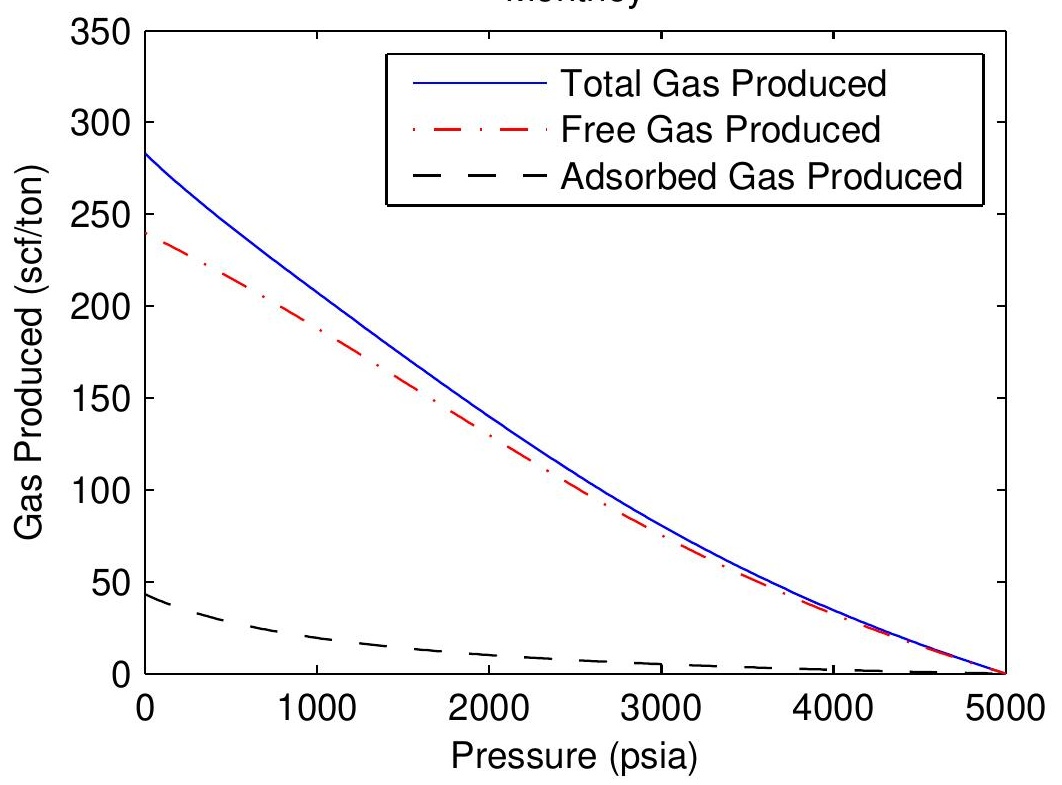


Figure_11

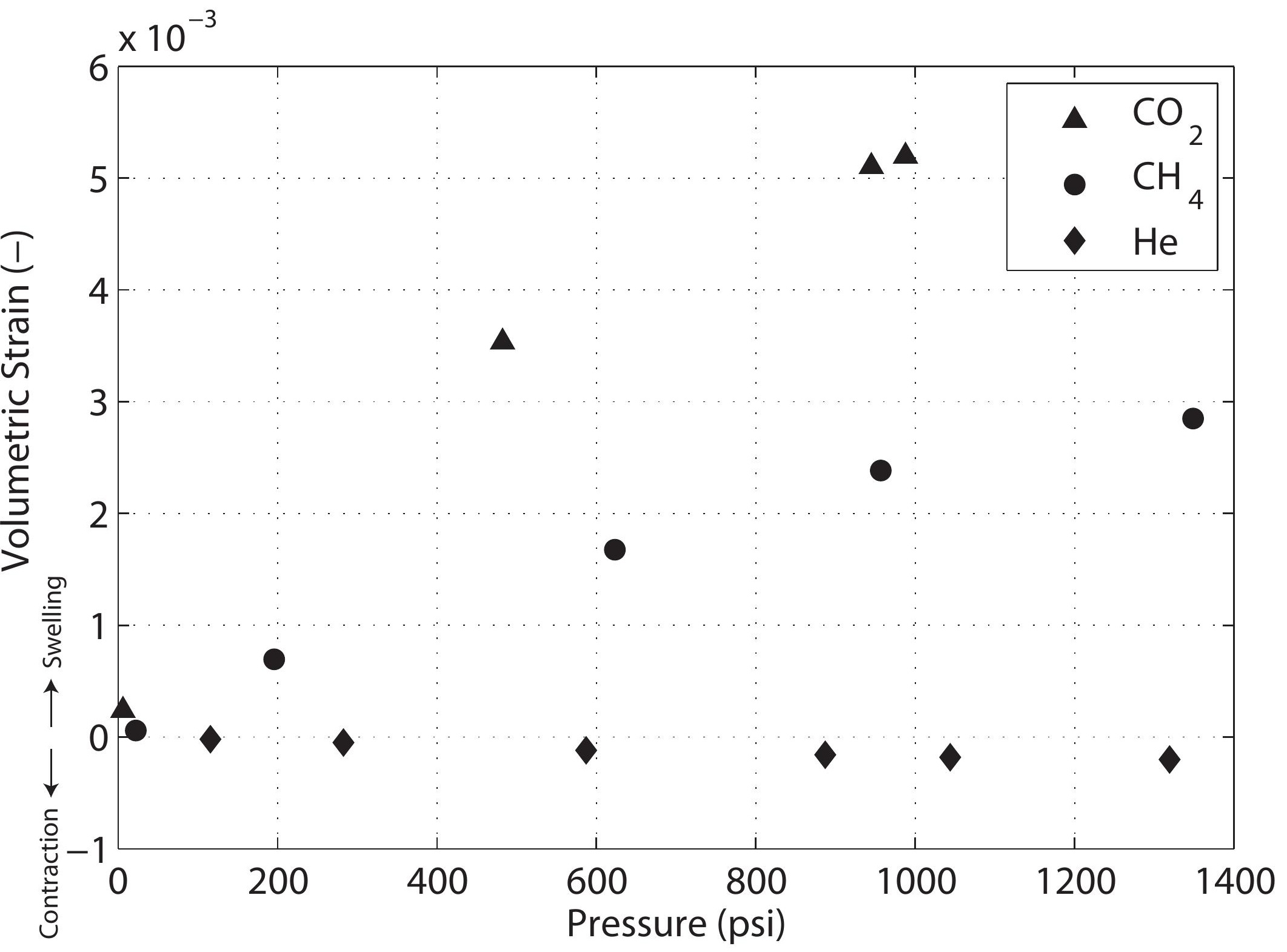

